\title{
On the friction and sliding wear of rubber/layered silicate nanocomposites
}

\author{
K. G. Gatos, K. Kameo, J. Karger-Kocsis* \\ Institut für Verbundwerkstoffe GmbH (Institute for Composite Materials), Kaiserslautern University of Technology, \\ Erwin Schrödinger Str. 58, D-67663 Kaiserslautern, Germany
}

Received 26 October 2006; accepted in revised form 11 December 2006

\begin{abstract}
The dry sliding and friction behaviors of organoclay modified hydrogenated nitrile (HNBR) and ethylene/propylene/diene (EPDM) rubbers were studied using a pin (steel)-on-plate (rubber sheet) test configuration. It was found that the organoclay modification may improve or deteriorate the resistance to wear of rubbers. The resistance to wear was adversely affected by pronounced intercalation/exfoliation and two-dimensional alignment of the clay layers (i.e. normal to the moving pin). This result is in analogy with the directional dependence of the wear performance of fiber-reinforced composite laminates.
\end{abstract}

Keywords: nanomaterials, polymer composites, rubber, wear, organoclay

\section{Introduction}

In recent years the research devoted to rubber/layered silicate nanocomposites was focused mainly on different compounding techniques, identifying the mechanisms involved in intercalation/exfoliation, improving the properties (like mechanical, gas barrier, thermal stability) and modifying the vulcanization (e.g. [1-10]). Although the wear of rubber components is of both practical relevance and scientific interest, the wear performance of rubber/ layered silicate nanocomposites has scarcely been addressed [11]. By contrast, several papers addressed already the wear performance of 'organoclay'-modified thermoplastics (e.g. [12-13]) and thermosets (e.g. [14-15]).

Unlike to the sliding wear of metals, ceramics or hard polymers, the mechanisms involved in rubber tribology are peculiar [16-17]. As a hard slider (indenter) passes continuously over a rubber surface, it generates a complicated compression-tension strain cycling at the contact and a

*Corresponding author, e-mail: karger@ivw.uni-kl.de

(C) BME-PT and GTE corresponding stress distribution around the indenter [17-19]. This creates regular folds, which cross the area of contact from compressive (front part) to the tensile zone (rear part), like wrinkles in a carpet. After the slider has passed and the rubber relaxes, the region around these folds turns back creating a characteristic abrasive pattern which is usually observed for rubbers. These 'waves of detachment', hampering true sliding between the surfaces, are often called 'Schallamach's waves' [17-19]. By this way, a saw tooth profile (crack growth) on the abraded rubber surface may form which is also termed 'tongue-like' pattern. The 'tongue-tip' bends backwards during sliding, ruptures and finally, it is peeled off completely. Consequently, as the sliding process of a hard slider on the soft rubber surface is not continuous, stick-slip motion or self-excited frictional vibration can be generated. Therefore, the tribology of elastomers encompasses complex wear mechanisms, which are affected by numerous parameters including also the type of the filler. 


\section{Experimental}

\subsection{Materials}

For the investigation of the wear performance of rubber/layered silicate nanocomposites, a hydrogenated acrylonitrile/butadiene rubber (HNBR) and an ethylene/propylene/diene rubber grafted with maleic anhydride (EPDM-MA) were selected as matrices. Montmorillonites, unmodified (MMT) and modified with various intercalants (i.e. octadecylamine - ODA; octadecyltrimethylammonium salt - ODTMA; and methyl-tallow-bis(2-hydroxyethyl) quaternary ammonium salt $-\mathrm{MTH})$, served as organoclays. In all rubber composites, produced by melt mixing, the filler content was fixed at 10 parts per hundred rubber (phr). As the compositions of the rubbers were different, $10 \mathrm{phr}$ organoclay in the HNBR and EPDM mixes corresponds to 7.8 and $8.4 \mathrm{wt} \%$, respectively. Characteristics of the materials used, their compounding procedure, the sulfur curing recipes, the characterization techniques along with the related results are described elsewhere for the rubber nanocomposites produced [20-22].

\subsection{Tests}

The wear characteristics were determined in a pinon-disk type sliding wear test, where the disk was the rubber specimen and the counterpart was a steel pin (316L stainless steel, 17-12 Mo). This configuration is also referred as 'pin-on-plate'. The pin ended in a hemisphere with a radius of curvature of $1.5 \mathrm{~mm}$. The applied normal force and sliding velocity were $3 \mathrm{~N}$ and $0.25 \mathrm{~m} / \mathrm{s}$ (144 revolutions per minute on the related tribometer), respectively. Tests were run at $T=23^{\circ} \mathrm{C}$ at $50-70 \%$ relative humidity. The density of the rubbers was determined by the Archimedes buoyancy method and their hardness with a Zwick Shore A tester (Ulm, Germany). The specific wear rate, given by the ratio of volume loss to the constant normal load (i.e. $3 \mathrm{~N}$ ) multiplied by the overall sliding distance, was computed accordingly.

\section{Results and discussion}

\subsection{HNBR micro- and nanocomposites}

As presented in Table 1, the HNBR/organo-MMT nanocomposites present enhanced tensile and tear strength values compared to the plain HNBR or the HNBR/MMT vulcanizates. Additionally, an increase in the hardness was observed owing to the clay reinforcement. On the other hand, the high elongation at break values of the compounds were maintained. The damping at $30^{\circ} \mathrm{C}$, as it is expressed by the mechanical loss factor value (delivered by dynamic mechanical thermal analysis, DMTA), is increasing for the HNBR/organoclay nanocomposites. The friction coefficient, representing a steadystate value, seems to be comparable for all rubber compounds, which contain MMT regardless of its modification. It is usually claimed that the abrasion of rubber correlates with the ultimate properties (i.e. tensile strength, elongation at break, tear resistance), whereas in respect to wear their fatigue and dynamic mechanical properties are of great importance [16]. Based on this rule of thumb the HNBR/organo-MMT nanocomposites (which fulfill these requirements) should possess excellent resistance to wear. As shown in Figure 1, this is not the case as the specific wear rate increased considerably for the HNBR/organoclay nanocomposites (especially for the HNBR/MMT-ODTMA and HNBR/MMT-MTH systems). The latter nanocomposites present intercalated/exfoliated structures opposed to the intercalated/deintercalated clay populations found in the HNBR/MMT-ODA vulcanizate [20]. On the contrary, for the HNBR/MMT microcomposite (the latter term is due to the fact that in this mixture the MMT was neither intercalated nor exfoliated) a reduced specific wear rate was measured. It was speculated that the reason for

Table 1. Characteristics of HNBR/layered silicate vulcanizates

\begin{tabular}{|c|c|c|c|c|c|}
\hline Property & HNBR & HNBR/MMT & HNBR/MMT-ODA & HNBR/MMT-ODTMA & HNBR/MMT-MTH \\
\hline Density $\left[\mathrm{g} / \mathrm{cm}^{3}\right]$ & 1.018 & 1.064 & 1.051 & 1.046 & 1.053 \\
\hline Hardness [Shore A] & 60 & 64 & 76 & 75 & 78 \\
\hline Tensile strength [MPa] & $15.2 \pm 1.8$ & $19.8 \pm 2.0$ & $31.5 \pm 1.4$ & $27.6 \pm 2.0$ & $31.8 \pm 1.0$ \\
\hline Elongation at break [\%] & $675 \pm 107$ & $660 \pm 26$ & $780 \pm 26$ & $707 \pm 45$ & $756 \pm 40$ \\
\hline Tear strength $[\mathrm{kN} / \mathrm{m}]$ & $8.8 \pm 1.3$ & $10.3 \pm 1.0$ & $42.6 \pm 0.6$ & $24.7 \pm 1.0$ & $38.6 \pm 2.0$ \\
\hline $\tan \delta\left(\right.$ at $\left.30^{\circ} \mathrm{C}\right)$ & 0.06 & 0.09 & 0.13 & 0.16 & 0.19 \\
\hline Friction coefficient & 0.41 & 0.50 & 0.53 & 0.53 & 0.49 \\
\hline Wear test duration $[\mathrm{h}]$ & 20 & 20 & 20 & 2 & 3.5 \\
\hline
\end{tabular}




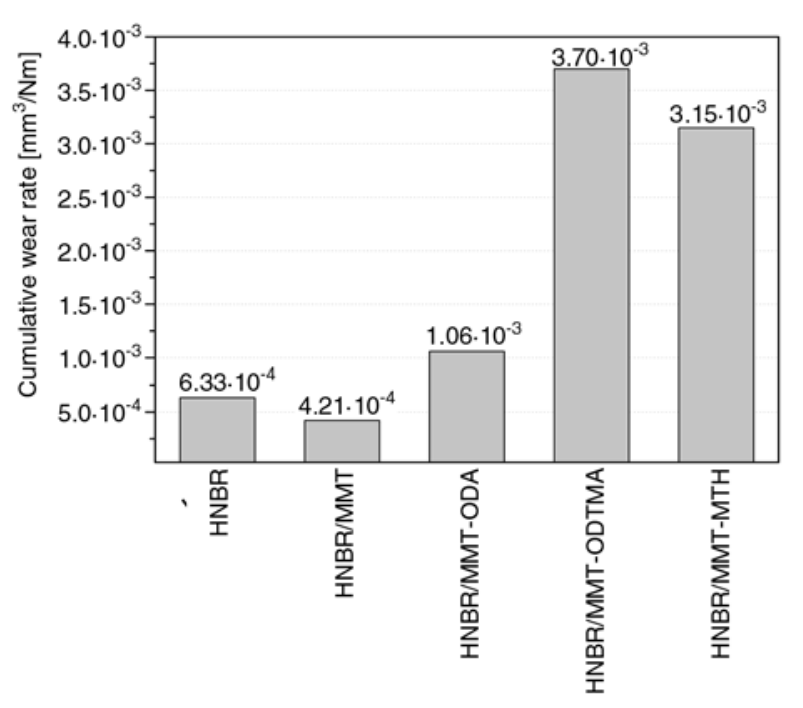

Figure 1. Specific wear rate of HNBR and HNBR containing various (organo)clay fillers in $10 \mathrm{phr}$ amount

this unexpected finding is the dispersion of the silicate layers in the HNBR matrix, which renders the rubber orthotropic owing to a two-dimensional (2D; in-plane) alignment of the clay layers and stacks. The silicate platelets were preferentially aligned parallel to the sliding direction according to transmission electron microscopic (TEM) inspection. This alignment is favored by the sheeting and compression molding of the calendered rubber during vulcanization. The $2 \mathrm{D}$ structuring of the clay platelets triggers a mechanism which is similar to a can opening procedure. 'Can-opening' mechanism is at work during the compression-extension strain cycle at the slider contact, and especially at the tensile zone at the rear part of the pin. Albeit the HNBR/MMT microcomposite has a similar friction coefficient as the corresponding nanocomposites (cf. Table 1), it has a lower wear rate compared to the nanocomposites. Note, that in this compound the dispersion of clay agglomerates yields a far less orthotropic behavior compared to the silicate dispersion of the nanocomposites. Additionally, this vulcanizate showed a hardness comparable with that of the pristine HNBR and a relatively low mechanical loss factor above room temperature (however, which is still higher than that of the plain HNBR). Thus, a lower hardness along with an 'isotropic reinforcement' (i.e. a 3D-type instead of a $2 \mathrm{D}$ version) may improve the wear performance of rubber/layered silicate systems. It is worth of noting that the above discussion presumes that the state of cure of the HNBR stocks is the same. This was, however, not checked. Further, the HNBR recipe contained substantial amount of plasticizer which might have affected the wear behavior.

\subsection{EPDM micro- and nanocomposites}

In order to get a clearer picture on this issue additional sliding wear tests were performed on EPDMMA/organoclay nanocomposites. Table 2 lists the characteristics of the EPDM-MA compounds tested. Note that their hardness is comparable. The ultimate properties of the EPDM-MA/organoclay nanocomposites are enhanced compared to the plain EPDM-MA. Moreover, the distribution of the silicate layers in the EPDM-MA matrix is more random (i.e. 3 D-type yielding an isotropic mechanical behavior) than in the case of the abovementioned HNBR compounds (cf. TEM images in Refs. [20] and [22]). The reason for this difference is linked with the compression molding procedure. To produce the EPDM-MA compounds attention was paid during sheeting on a two-rolls mill to work with a large opening between the rolls. Thus, a better resistance to abrasive wear was expected via suppressing the processing-induced 2D layering of the organoclay particles causing the above mentioned 'can-opening' mechanism. The slight increase of the hardness of the EPDM-MA nanocomposites contributes additionally to a better resistance to abrasion. Interesting to observe the drastic decrease in the steady-state friction coefficient for the nanocomposites. For the EPDM-MA compound some adhesion between the hard metal slider and the polar EPDM-MA matrix (because of

Table 2. Characteristics of EPDM-MA/layered silicate vulcanizates

\begin{tabular}{|l|c|c|c|}
\hline \multicolumn{1}{|c|}{ Property } & EPDM-MA & EPDM-MA/MMT-ODA & EPDM-MA/MMT-ODTMA \\
\hline Density $\left[\mathrm{g} / \mathrm{cm}^{3}\right]$ & 0.915 & 0.956 & 0.965 \\
\hline Hardness $[$ Shore A] & 70 & 74 & 74 \\
\hline Tensile strength $[\mathrm{MPa}]$ & $2.7 \pm 0.8$ & $12.8 \pm 2.1$ & $4.1 \pm 0.6$ \\
\hline Elongation at break $[\%]$ & $174 \pm 10$ & $292 \pm 50$ & $9.3 \pm 20$ \\
\hline Tear strength $[\mathrm{kN} / \mathrm{m}]$ & $5.8 \pm 0.6$ & $9.4 \pm 1.5$ & 0.053 \\
\hline $\tan \delta$ at $30^{\circ} \mathrm{C}$ ) & 0.003 & 0.029 & 0.42 \\
\hline Friction coefficient & 1.05 & 0.61 & 8 \\
\hline Wear test duration $[\mathrm{h}]$ & 10 & 10 & \\
\hline
\end{tabular}


the maleic anhydride groups) can be supposed. When the EPDM-MA is compounded with the organoclay, the polar maleic anhydride groups are involved in the interactions with the organoclay and thus they affect the adhesion with the metal slider in lesser extent. If this speculation holds then this aspect should also be considered for rubber compounds apart from the abrasive and fatigue type wear contributions. As shown in Figure 2, the specific wear rate of the EPDM-MA/organoclay nanocomposites is below that of the plain EPDM rubber. Scanning electron microscopic (SEM) images taken from the worn surfaces of the rubber plates are very informative (cf. Figure 3 ). The sliding direction of the pin is indicated in the figures by an arrow. The abraded surface of the EPDM-MA vulcanizate shows a track with rough ridges and dimples. The worn track even suggests the occurrence of some kind of stick-slip mechanism during sliding (cf. Figure 3a). By contrast, the EPDMMA/organoclay vulcanizates present nicely the 'Schallamach's waves' (cf. Figure 3b and 3c). Note that on the worn surface of EPDM-MA/MMTODTMA these 'waves of detachment' are smaller and closer packed than for EPDM-MA/MMTODA. This may suggests a finer dispersion of the silicate sheets in the former system which was proved, in fact [22]. Recall that the EPDM-MA/ MMT-ODA nanocomposite contained also deintercalated organoclay stacks [21]. Swelling tests indicated that the state of cure of the EPDM stocks was practically the same. As a consequence, the effects

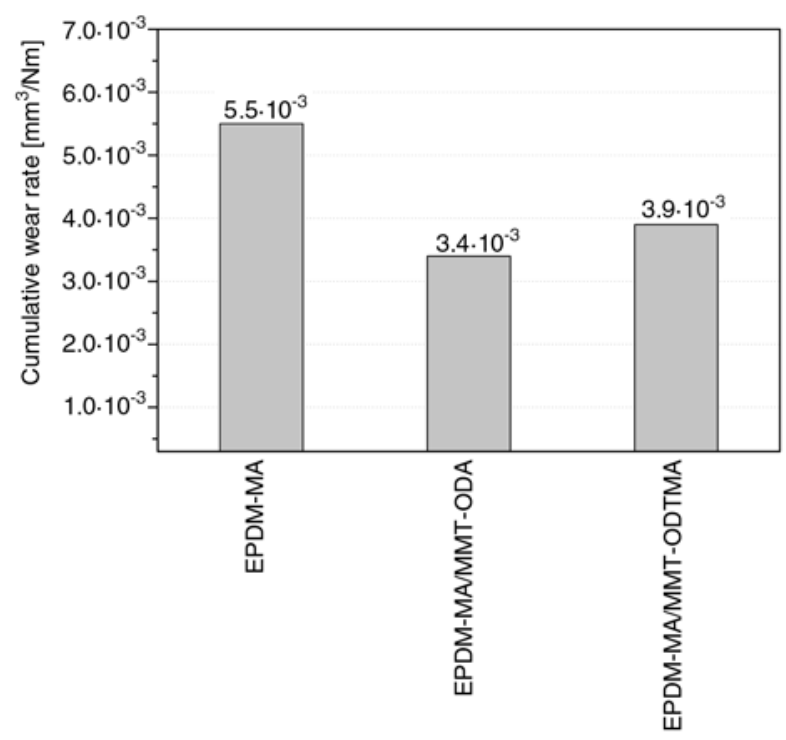

Figure 2. Specific wear rate of EPDM-MA and EPDMMA/organoclay containing $10 \mathrm{phr}$ filler listed above are likely correctly traced to the dispersion and orientation of the clay layers and aggregates.
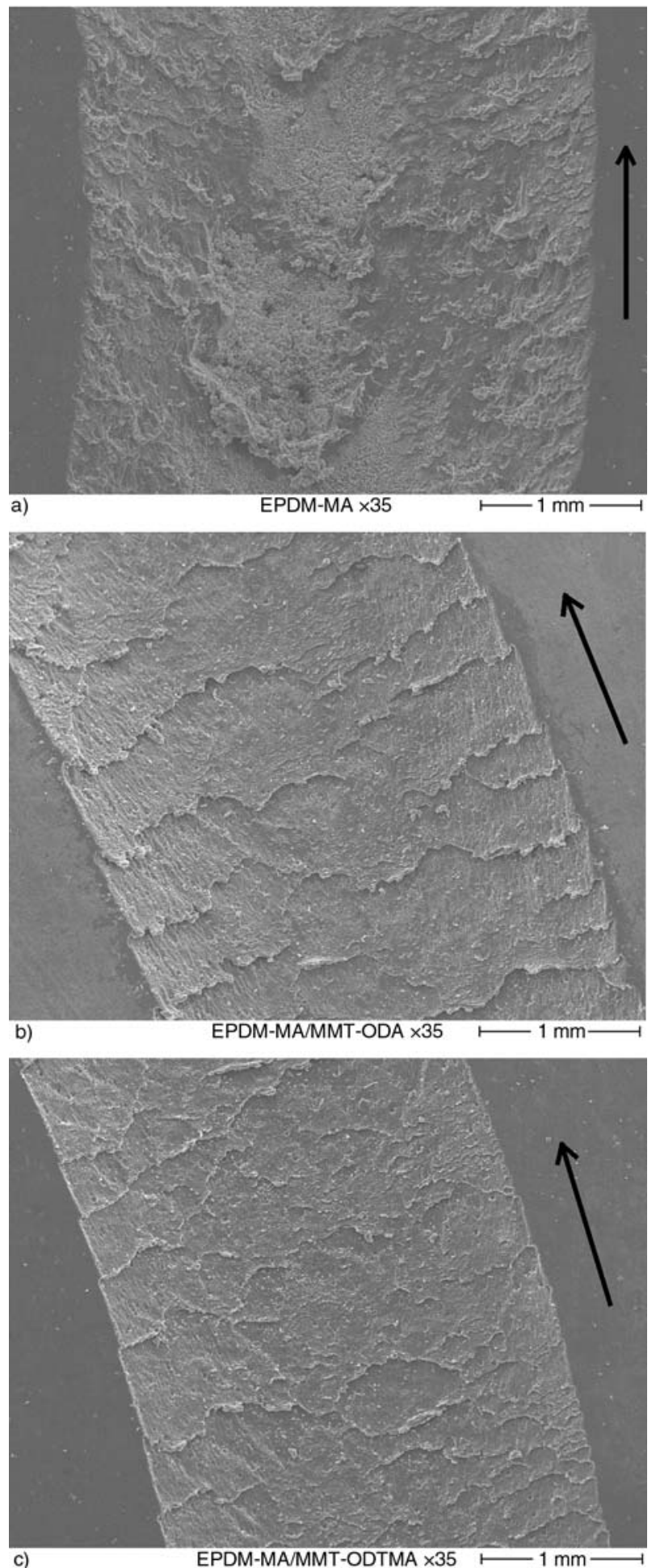

Figure 3. Wear track of EPDM-MA/layered silicate vulcanizates: (a) EPDM-MA, (b) EPDM-MA reinforced with MMT-ODA and (c) EPDM-MA reinforced with MMT-ODTMA.

Note: organo-MMT content is $10 \mathrm{phr}$ 


\section{Conclusions}

Incorporation of layered silicates in rubber can affect the wear performance of the related vulcanizate favorably or unfavorably. The final outcome depends on those parameters, which affect the abrasive, fatigue and adhesive wear components. Note that this is the state-of-wisdom with rubbers containing 'traditional' fillers. Our preliminary results suggest that the dispersion and especially the orientation of the silicate platelets in the rubber matrix are crucial. Alignment of the clay platelets in plane (2D resulting in an orthotropic character), i.e. parallel to the sliding direction may be disadvantageous. The 2D clay alignment triggers a mechanism during sliding, which has some similarities with a 'can-opening' process. This may reduce the resistance to wear markedly.

\section{Acknowledgements}

This work was performed in the framework of an Integrated Project of the EU (KRISTAL; Contract Nr.: NMP3-CT2005_515837)

\section{References}

[1] Ganter M., Gronski W., Semke H., Zilg T., Thomann C., Mühlhaupt R.: Surface-compatibilized layered silicates - A novel class of nanofillers for rubbers with improved mechanical properties. Kautschuk, Gummi, Kunststoffe, 54, 166-171 (2001).

[2] Joly S., Garnaud G., Ollitrault R., Bokobza L., Mark J. E.: Organically modified layered silicates as reinforcing fillers for natural rubber. Chemistry of Materials, 14, 4202-4208 (2002).

[3] Arroyo M., López-Manchado M. A., Herrero B.: Organo-montmorillonite as substitute of carbon black in natural rubber compounds. Polymer, 44, 24472453 (2003).

[4] Varghese S., Karger-Kocsis J., Gatos K. G.: Melt compounded epoxidized natural rubber/layered silicate nanocomposites: structure-properties relationships. Polymer, 44, 3977-3983 (2003).

[5] Zheng H., Zhang Y., Peng Z., Zhang Y. X.: Influence of clay modification on the structure and mechanical properties of EPDM/montmorillonite nanocomposites. Polymer Testing, 23, 217-223 (2004).

[6] Zheng H., Zhang Y., Peng Z, Zhang Y. X.: A comparison between cure systems for EPDM/montmorillonite nanocomposites. Polymers \& Polymer Composites, 12, 197-206 (2004).

[7] Wu Y-P., Ma Y., Wang Y-Q., Zhang L-Q.: Effects of characteristics of rubber, mixing and vulcanization on the structure and properties of rubber/clay nanocomposites by melt blending. Macromolecular Materials and Engineering, 289, 890-894 (2004).
[8] Karger-Kocsis J., Wu C-M.: Thermoset rubber/layered silicate nanocomposites. Status and future trends. Polymer Engineering and Science, 44, 1083-1093 (2004).

[9] Hwang W-G., Wei K-H., Wu C-M.: Mechanical, thermal, and barrier properties of NBR/organosilicate nanocomposites. Polymer Engineering and Science, 44, 2117-2124 (2004).

[10] Liang Y-R., Lu Y-L., Wu Y-P., Ma Y., Zhang L-Q.: Pressure, the critical factor governing final microstructures of cured rubber/clay nanocomposites. Macromolecular Rapid Communications, 26, 926931 (2005).

[11] Karger-Kocsis J.: Dry friction and sliding wear behavior of organoclay reinforced thermoplastic polyurethane rubbers. Kautschuk, Gummi, Kunststoffe, 59, 537-543 (2006).

[12] Lai S-Q., Li T-S., Liu X-J., Lu R-G.: A study on the friction and wear behavior of PTFE filled with acid treated nano-attapulgite. Macromolecular Materials and Engineering, 289, 916-922 (2004).

[13] Srinath G., Gnanamoorthy R.: Effects of nanoclay reinforcement on tensile and tribo behaviour of nylon 6. Journal of Materials Science, 40, 2897-2901 (2005).

[14] Jawahar P., Gnanamoorthy R., Balasubramanian M.: Flexural and tribological properties of polyester-clay nanocomposites. Journal of Materials Science, 40, 4391-4393 (2005).

[15] Lin J-C.: Compression and wear behavior of composites filled with various nanoparticles. Composites: Part B, 38, 79-85 (2007).

[16] Grellmann W., Heinrich G., Cäsar T.: Crack initiation, wear and molecular structure of filled vulcanized materials. in 'Deformation and fracture behavior of polymers' (eds.: Grellmann W. and Seidler S.), Springer, Berlin, 479-492 (2001).

[17] Zhang S-W.: Tribology of elastomers. Elsevier, Amsterdam, 2004.

[18] Schallamach A.: How does rubber slide? Wear, 17, 301-312 (1971).

[19] Barquins M.: Adherence, friction and wear of rubberlike materials. Wear, 158, 87-117 (1992).

[20] Gatos K. G., Sawanis N. S., Apostolov A. A., Thomann R., Karger-Kocsis J.: Nanocomposite formation in hydrogenated nitrile rubber (HNBR)/ organo-montmorillonite as a function of the intercalant type. Macromolecular Materials and Engineering, 289, 1079-1086 (2004).

[21] Gatos K. G., Thomann R., Karger-Kocsis J.: Characteristics of ethylene propylene diene monomer rubbers/organoclay nanocomposites resulting from different processing conditions and formulations. Polymer International, 53, 1191-1197 (2004).

[22] Gatos K. G., Karger-Kocsis J.: Effects of primary and quaternary amine intercalants on the orgnoclay dispersion in a sulfur-cured EPDM rubber. Polymer, 46, 3069-3076 (2005). 